\title{
Desempenho de novilhos suplementados com sais proteinados em pastagem nativa
}

\author{
Marcelo Knorr(1), Harold Ospina Patino(1), André Luís Finkler da Silveira ${ }^{(1)}$, Paulo Roberto Frenzel Mühlbach(1), \\ Giovanni Matheus Mallmann ${ }^{(1)}$ eFabio Schuler Medeiros ${ }^{(1)}$
}

\begin{abstract}
(1)Universidade Federal de Rio Grande do Sul, Fac. de Agronomia, Dep. de Zootecnia, Av. Bento Gonçalves, no 7712, Bairro Agronomia, CEP 90540-000 Porto Alegre, RS. E-mail: 0001051@ufrgs.br, ospina@orion.ufrgs.br, andrefinker@pop.com.br, fsmedeiros@terra.com.br, gmmallmann@hotmail.com, muhlbach@orion.ufrgs.br
\end{abstract}

Resumo - O objetivo deste trabalho foi avaliar o efeito da suplementação com sais proteinados sobre o desempenho de novilhos em pastagem nativa diferida, no Rio Grande do Sul, Brasil. Os suplementos de sal proteinado avaliados foram: com uréia, com amiréia, com amiréia mais levedura e sal mineral. O experimento teve duração de 118 dias e foram utilizadas 8 parcelas com área de 7,5 ha, cada uma com 8 novilhos, de peso médio 264 kg, com idade de 18 meses, em delineamento completamente casualizado. A pastagem apresentou valores médios de 6,8\% de proteína bruta, $73,3 \%$ de fibra em detergente neutro, e $42,5 \%$ de digestibilidade in vitro da matéria orgânica, sem que fossem detectadas diferenças significativas entre tratamentos. O ganho médio diário $(0,287 \mathrm{~kg})$ dos animais suplementados com o sal proteinado com amiréia e levedura, foi superior ao apresentado pelos animais que consumiram sal mineralizado $(0,019 \mathrm{~kg})$ mas não houve diferenças entre uréia $(0,159 \mathrm{~kg})$ e amiréia $(0,124 \mathrm{~kg})$. O consumo diário dos suplementos proteinados $(0,400 \mathrm{~kg})$ foi superior ao consumo do suplemento mineral $(0,038 \mathrm{~kg})$. A adição de levedura ativa, ao sal proteinado formulado com amiréia, melhora o desempenho de novilhos em pastagem nativa diferida.

Termos para indexação: suplementação protéica, uréia, amiréia, levedura, campo nativo.

\section{Performance of steers supplemented with protein salts on native pastures}

\begin{abstract}
The objective of this work was to evaluate the effect of protein salts supplementation on performance of beef steers grazing differed native pasture in Rio Grande do Sul State, Brazil. Protein salts were supplemented with: urea, starea, starea plus yeast, and mineral salt. The experiment was conducted during 118 days, and utilized 8 paddocks with 7.5 ha each one, with 8 steers averaging $264 \mathrm{~kg}$ and 18 months old, in a completely randomized design. Average composition of pasture was $6.8 \%$ of crude protein, $73.3 \%$ of neutral detergent fiber, and $42.5 \%$ in vitro organic matter digestibility; significative differences weren't detected among treatments. Average daily weight gain of animals fed protein salt with starea plus yeast $(0.287 \mathrm{~kg})$, was higher than the weight gain of animals fed mineral salt (0.019 kg); differences weren't detected among urea $(0.159 \mathrm{~kg})$ and starea $(0.124 \mathrm{~kg})$. Daily intake of protein supplements ( $0.400 \mathrm{~kg}$ ) was higher than that of mineral supplement $(0.038 \mathrm{~kg})$. Addition of live yeast to the protein salt formulated with starea resulted in better performance of steers grazing differed native pasture.
\end{abstract}

Index terms: protein supplementation, urea, starea, yeast, native pasture.

\section{Introdução}

A exploração da pecuária de corte gaúcha é desenvolvida, basicamente, mediante sistemas extensivos, com a utilização das pastagens nativas como a principal fonte de forragem para alimentação animal. Essas pastagens ocupam uma área aproximada de 11,7 milhões de hectares que representam, aproximadamente, $54 \%$ da área total do Estado, e comporta um rebanho bovino com 13,2 milhões de cabeças (IBGE, 1996). Como principal característica, essas pastagens apresentam uma grande biodiversidade, cuja maior produção e qualidade ocorre no período da primavera-verão (Ospina \& Medeiros, 2003).

Do ponto de vista nutricional, o período crítico para os sistemas de produção, fundamentados na utilização de pastagem nativa, são os meses de inverno, em virtude dos baixos teores de proteína bruta e dos altos teores de fibra em detergente neutro lignificada, apresentados pelas pastagens nessa época do ano. 
O baixo nível de proteína é um fator limitante ao crescimento dos microrganismos ruminais, o que causa uma lenta degradação da forragem ingerida, maior tempo de retenção do alimento no rúmen e menor consumo de nutrientes pelos animais (Soest, 1994). Nessas condições, são observados baixos índices zootécnicos, com perdas de peso que podem atingir até $30 \%$ do peso vivo no inverno (Barcellos et al., 1999), podem aumentar a idade de abate e piorar a qualidade do produto final, deixando como resultado redução na receita do produtor e ineficiência no sistema de produção.

Uma das alternativas existentes para reverter o quadro anterior é a utilização da suplementação protéica de animais, que consomem pastagens nativas diferidas no verão-outono. Em situações onde existe uma boa disponibilidade de matéria seca na pastagem (2000-2500 kg), a suplementação protéica pode reduzir as perdas de peso no inverno e proporcionar ganhos de peso da ordem de $300 \mathrm{~g}_{\text {animal }}{ }^{-1} \mathrm{dia}^{-1}$ (Zanetti et al., 2000).

Alguns resultados de pesquisas indicam que os principais efeitos da suplementação protéica, em volumoso de baixa qualidade, estão relacionados com melhorias na eficiência da fermentação ruminal, velocidade de degradação ruminal da fibra e no consumo de volumoso (Köster et al., 1996; Mathis et al., 2000). Essas respostas podem ser maximizadas pela otimização da relação entre o consumo de proteína bruta degradável no rúmen e o consumo de matéria orgânica digestível na dieta consumida pelos animais (Bodine \& Purvis, 2003).

O objetivo deste trabalho foi avaliar o efeito da suplementação com sais proteinados sobre o desempenho de bovinos de corte mantidos durante o inverno em campo nativo diferido.

\section{Material e Métodos}

O trabalho foi realizado na Fazenda São Lucas, localizada no município de São Borja, região fisiográfica da Campanha, no sudoeste do Rio Grande do Sul, situada a $28^{\circ} 55^{\prime} 40^{\prime \prime} \mathrm{S}$ e a $55^{\circ} 47^{\prime} 50,5^{\prime \prime}$ W. As análises laboratoriais foram feitas no Departamento de Zootecnia da UFRGS.

Os suplementos avaliados de sal proteinado foram formulados à base de: uréia (SPU), amiréia (SPA), amiréia mais levedura (Procreatin 7) (SPAL) e sal mineral (SM).

As fórmulas foram feitas para obter-se uma relação entre o consumo de proteína degradável no rúmen e consumo de matéria orgânica digestível (CPBDR:CMOD) de 11\% (NRC, 1996), e isto foi feito a partir de análises (degradabilidade da proteína bruta e digestibilidade in vitro da matéria orgânica) e estimativas de consumo de matéria seca, feitas em amostras da pastagem, coletadas antes do início do experimento. O consumo diário dos sais proteinados foi estimado em torno de $0,15 \%$ do peso vivo, controlado pelo nível de cloreto de sódio no suplemento.

Os sais proteinados foram elaborados na fábrica de rações da Cooperativa Tritícola Samborjense (Cotrisal), no município de São Borja, utilizando-se os seguintes ingredientes na formulação: farelo de arroz integral, farelo de trigo, farelo de soja, uréia, amiréia (150S), cloreto de sódio, premix mineral (Fosbovi Pronto), carbonato de cálcio, farinha de ossos calcinada e levedura ativa (Procreatin 7). O suplemento com levedura ativa foi formulado para fornecer em torno de $1 \mathrm{~g}$ por animal ao dia, num total de 20 bilhões de UFC. O premix mineral, utilizado na formulação dos suplementos protéicos, foi o mesmo sal mineralizado utilizado para o tratamento controle (Fosbovi Pronto). A composição química dos suplementos é apresentada na Tabela 1.

A área experimental utilizada foi uma pastagem nativa, diferida durante 102 dias (de 16 de fevereiro a 30 de maio de 2003), dividida por cercas elétricas em 8 parcelas, com áreas em torno de 7,5 ha. Cada parcela continha um cocho coberto, com $2 \mathrm{~m}$ de comprimento e acesso dos dois lados, e aguadas.

O campo nativo apresentava uma boa condição de cobertura vegetal, considerado de boa qualidade, pela contribuição de diversas espécies de gramíneas e

Tabela 1. Composição bromatológica dos suplementos: sal proteinado com uréia (SPU), sal proteinado com amiréia (SPA), sal proteinado com amiréia e levedura (SPAL), e sal mineral (SM).

\begin{tabular}{|c|c|c|c|c|}
\hline Composição bromatológica & SPU & SPA & SPAL & SM \\
\hline Matéria seca $(\%)$ & 87,49 & 88,42 & 88,24 & 92,33 \\
\hline Matéria orgânica (\% MS) & 66,01 & 65,02 & 66,32 & 7,90 \\
\hline Proteína bruta (\% MS) & 41,43 & 41,71 & 41,08 & 0,00 \\
\hline $\begin{array}{l}\text { Equivalente protéico em } \\
\text { nitrogênio não-protéico }(\% \mathrm{MS})\end{array}$ & 26,16 & 26,27 & 26,19 & 0,00 \\
\hline \multicolumn{5}{|l|}{ Composição mineral (\% MS) } \\
\hline $\mathrm{Ca}(\%)$ & 5,9 & 6,6 & 7,0 & 6,0 \\
\hline $\mathrm{P}(\%)$ & 3,7 & 3,4 & 3,9 & 4,5 \\
\hline $\mathrm{S}(\%)$ & 0,22 & 0,70 & 0,73 & 0,4 \\
\hline $\mathrm{Na}(\%)$ & 0,4 & 0,4 & 0,4 & 16 \\
\hline $\mathrm{Cu}\left(\mathrm{mg} \mathrm{kg}^{-1}\right)$ & 123 & 135 & 163 & 1.050 \\
\hline $\mathrm{Co}\left(\mathrm{mg} \mathrm{kg}^{-1}\right)$ & 3,39 & 3,15 & 3,14 & 38,9 \\
\hline $\mathrm{Zn}\left(\mathrm{mg} \mathrm{kg}^{-1}\right)$ & 167 & 193 & 209 & 2.200 \\
\hline $\mathrm{Fe}\left(\mathrm{mg} \mathrm{kg}^{-1}\right)$ & 1.141 & 1.357 & 1.587 & 1.300 \\
\hline $\operatorname{Mn}\left(\mathrm{mg} \mathrm{kg}^{-1}\right)$ & 203 & 195 & 211 & 1.000 \\
\hline $\mathrm{Se}\left(\mathrm{mg} \mathrm{kg}^{-1}\right)$ & 0,93 & 0,86 & 0,86 & 9,0 \\
\hline
\end{tabular}


leguminosas que compõem a flora nativa dessa região do Estado: grama-forquilha (Paspalum notatum), capim-melador (Paspalum dilatatum), grama-tapete (Axonopus compressus), pega-pega (Desmodium pratensis) e trevo nativo (Tripholium polimorphum).

Foram utilizados 64 novilhos sem raça definida, provenientes de cruzas entre raças predominantemente européias, com peso médio de 264 kg, e média de idade de 18 meses. No início do experimento, os animais foram estratificados por peso e distribuídos aleatoriamente nos respectivos tratamentos, com 8 animais por parcela. Os animais permaneceram durante 118 dias (30 de maio a 25 de setembro) na pastagem, foram manejados sob pastejo contínuo e receberam suplementação à vontade.

O consumo de suplemento foi avaliado para o período total do experimento, descontando-se as sobras da oferta total de suplemento. Para avaliação do desempenho, os animais foram pesados em jejum alimentar e hídrico de 12 horas, com intervalos de 28 dias para os períodos 1 , 3 e 4, e com intervalo de 34 dias para o período 2. Em razão de os animais não terem sido previamente adaptados aos tratamentos, o primeiro período experimental foi utilizado como período de adaptação e não foi considerado na avaliação dos dados.

Além do desempenho animal, foi avaliada a massa de pastagem e sua composição bromatológica, no início de cada período, e no final do último período. Para se estimar a massa de pastagem de cada parcela, a cada 28 dias, foram coletadas 7 amostras de $0,25 \mathrm{~m}^{2}$, cortadas rente ao solo; essas amostras foram secadas em estufa de ar forçado a $60^{\circ} \mathrm{C}$, por 72 horas, para posterior pesagem. A composição bromatológica foi avaliada em amostras de pasto coletadas simulando-se o pastejo animal, e analisadas quanto ao teor de proteína bruta (PB), fibra em detergente neutro (FDN), fibra em detergente ácido (FDA) (AOAC, 1995), e digestibilidade in vitro verdadeira da matéria orgânica (DIVMO) (Soest \& Robertson, 1985).

Para determinação da relação entre proteína bruta e nutrientes digestíveis totais (PB:NDT), considerou-se que uma unidade percentual da DIVMO equivaleria a uma unidade percentual de NDT.

O delineamento experimental utilizado foi completamente casualizado, com 4 tratamentos e 2 repetições, e as médias de tratamentos foram comparadas pelo teste de Tukey $(\mathrm{p}<0,05)$. Como foram efetuadas 3 observações no tempo, para cada unidade experimental, os da- dos foram analisados utilizando-se um desenho de parcelas subdivididas, o período foi considerado na sub-parcela, segundo o seguinte modelo matemático:

$\mathrm{Y}_{\mathrm{ijkl}}=\mu+\mathrm{T}_{\mathrm{i}}+\mathrm{A}(\mathrm{T})_{\mathrm{ij}}+\mathrm{P}_{\mathrm{k}}+(\mathrm{TP})_{\mathrm{ik}}+\mathrm{e}_{\mathrm{ijk} \mathrm{k}}$ onde: $Y_{\mathrm{ijkl}}$ é a l-ésima observação, no i-ésimo tratamento e no k-ésimo período; $\mu$ é o efeito médio; $T_{i}$ é o efeito do i-ésimo tratamento $(\mathrm{i}=1,2,3,4) ; \mathrm{A}(\mathrm{T})_{\mathrm{ij}}$ é o efeito do j-ésimo animal, dentro do i-ésimo tratamento (erro a); $\mathrm{P}_{\mathrm{k}}$ é o efeito do k-ésimo período (j=1, 2, 3); (TP) ${ }_{\mathrm{ik}}$ é o efeito da ik-ésima interação entre tratamento e período; $\mathrm{e}_{\mathrm{ijkl}}$ é o l-ésimo erro, associado à ijkl-ésima observação (erro b).

\section{Resultados e Discussão}

Não houve interação entre tratamento e período, quanto à qualidade da pastagem; as respostas diferenciadas, para cada tratamento, não foram decorrentes de alterações ocorridas no período de avaliação.

Os resultados das características avaliadas não foram diferentes entre os tratamentos, podendo-se afirmar que os resultados de desempenho, apresentados pelos animais, nesse experimento, foram decorrentes do efeito dos tratamentos utilizados (Tabela 2).

A qualidade e a massa de pastagem foram afetadas pelo período de avaliação (Tabela 3). A massa de pastagem (MP) sofreu uma redução de $42,4 \%$ entre os meses de junho e setembro (3.386 x $1.951 \mathrm{~kg} \mathrm{ha}^{-1}$ ), que pode ser explicada pelo consumo constante de pastagem e pelo aumento da carga animal, no período de avaliação, associados a um período de latência no crescimento da pastagem. Os níveis de MP se mantiveram

Tabela 2. Massa de pastagem (MP) e teores de proteína bruta (PB), fibra em detergente neutro (FDN), fibra em detergente ácido (FDA), digestibilidade in vitro da matéria orgânica (DIVMO), e a relação entre nutrientes digestíveis totais e proteína bruta (NDT:PB) da pastagem nativa, em cada um dos suplementos avaliados: sal proteinado com uréia (SPU), sal proteinado com amiréia (SPA), sal proteinado com amiréia e levedura (SPAL), e sal mineral (SM) ${ }^{(1)}$.

\begin{tabular}{lrrrr}
\hline Variável & SPU & SPA & SPAL & \multicolumn{1}{c}{ SM } \\
\hline MP $\left(\mathrm{kg} \mathrm{MS} \mathrm{ha}^{-1}\right)$ & $2.645 \mathrm{a}$ & $2.844 \mathrm{a}$ & $2.822 \mathrm{a}$ & $2.838 \mathrm{a}$ \\
PB (\%) & $6,6 \mathrm{a}$ & $6,7 \mathrm{a}$ & $7,0 \mathrm{a}$ & $7,0 \mathrm{a}$ \\
FDN (\%) & $74,1 \mathrm{a}$ & $73,1 \mathrm{a}$ & $72,4 \mathrm{a}$ & $73,8 \mathrm{a}$ \\
FDA (\%) & $45,7 \mathrm{a}$ & $46,9 \mathrm{a}$ & $46,2 \mathrm{a}$ & $44,3 \mathrm{a}$ \\
DIVMO (\%) & $42,7 \mathrm{a}$ & $42,4 \mathrm{a}$ & $43,1 \mathrm{a}$ & $41,7 \mathrm{a}$ \\
NDT:PB & $6,5 \mathrm{a}$ & $6,3 \mathrm{a}$ & $6,1 \mathrm{a}$ & $6,0 \mathrm{a}$ \\
\hline
\end{tabular}

${ }^{(1)}$ Médias na mesma linha, com letras iguais, não diferem entre si pelo teste de Tukey a $5 \%$ de probabilidade. 
acima dos $1.500 \mathrm{~kg} \mathrm{ha}^{-1}$, propostos por Pascoal \& Restle (1997), citados por Alves Filho et al. (2000), como limitantes à capacidade de enchimento ruminal, quando animais pastejam campos nativos finos. Pode-se esperar que somente fatores nutricionais, como a digestibilidade e o tempo de retenção ruminal, possam ter influenciado o consumo de forragem pelos animais (Poppi et al., 1987).

Os teores de proteína bruta (PB) da pastagem não foram diferentes nos primeiros 3 períodos de avaliação (6,6; 6,4 e 6,7) e estavam em níveis considerados marginais para o crescimento dos microrganismos ruminais e para o consumo de volumosos, que seria de $7 \%$ (Minson, 1990; Cochran et al., 1998). Porém, no ultimo mês de avaliação (setembro), ocorreu um aumento de 13,6\% no nível de proteína da pastagem $(6,57$ x 7,6), e superou o valor considerado crítico ao desempenho animal. Os valores de PB observados nesse experimento são similares aos descritos por Ospina \& Medeiros (2003), que revisaram diversos trabalhos e encontraram um valor médio de $6 \%$, durante o inverno, para pastagens nativas do Rio Grande do Sul.

A pastagem apresentou uma redução de $4,6 \%$ nos níveis de fibra em detergente neutro (FDN), no decorrer dos períodos de avaliação; os meses de junho e setembro apresentaram, respectivamente, o maior e o menor nível de FDN (74,8 e 72,1). O nível de fibra em detergente ácido apresentou uma redução no mês de setembro em relação aos meses de junho e julho (46,6\% e $46,3 \%$ x 44,2\%). Os altos valores de FDN e FDA estão relacionados ao estado de maturação da pastagem que com o diferimento prévio, realizado ao início do experimento, aumentou a proporção de plantas adultas, em relação às plantas em estágio vegetativo.

Tabela 3. Massa de pastagem (MP) e teores de proteína bruta (PB), fibra em detergente neutro (FDN), fibra em detergente ácido (FDA), digestibilidade in vitro da matéria orgânica (DIVMO), e a relação entre nutrientes digestíveis totais e proteína bruta (NDT:PB) da pastagem nativa, avaliada nos diferentes meses ${ }^{(1)}$.

\begin{tabular}{lrccc}
\hline Variável & Junho & Julho & Agosto & Setembro \\
\hline MP (kg MS ha $\left.{ }^{-1}\right)$ & $3.386 \mathrm{a}$ & $3.076 \mathrm{ab}$ & $2.736 \mathrm{~b}$ & $1.951 \mathrm{c}$ \\
PB (\%) & $6,6 \mathrm{~b}$ & $6,4 \mathrm{~b}$ & $6,7 \mathrm{~b}$ & $7,6 \mathrm{a}$ \\
FDN (\%) & $74,8 \mathrm{a}$ & $73,4 \mathrm{ab}$ & $73,1 \mathrm{ab}$ & $72,1 \mathrm{~b}$ \\
FDA (\%) & $46,6 \mathrm{a}$ & $46,3 \mathrm{a}$ & $46,1 \mathrm{ab}$ & $44,2 \mathrm{~b}$ \\
DIVMO (\%) & $38,2 \mathrm{~b}$ & $38,6 \mathrm{~b}$ & $45,7 \mathrm{a}$ & $47,4 \mathrm{a}$ \\
NDT:PB & $5,8 \mathrm{~b}$ & $6,0 \mathrm{~b}$ & $6,8 \mathrm{a}$ & $6,3 \mathrm{ab}$ \\
\hline
\end{tabular}

${ }^{(1)}$ Médias na mesma linha, com letras iguais, não diferem entre si pelo teste de Tukey a $5 \%$ de probabilidade.
A digestibilidade in vitro da matéria orgânica (DIVMO) da pastagem foi inferior nos meses de junho e julho (38,2\% e 38,6\%), se comparados aos meses de agosto e setembro (45,7\% e 47,4\%). Salomoni et al. (1988) informaram valores médios de DIVMO para pastagem nativa no RS, inferiores $(26,46 \%, 35,02 \%$, $30,13 \%$ e $41,02 \%$ ) nos meses de junho a setembro, se comparados aos valores observados nesse experimento. $\mathrm{O}$ aumento do teor de PB e da DIVMO, e a diminuição dos níveis de FDN e FDA, principalmente no mês de setembro, podem ser justificados em função de uma melhora nas condições climáticas (temperatura e a luminosidade), que resultam na rebrota da pastagem.

A análise da relação entre o conteúdo de nutrientes digestíveis totais, e proteína bruta (NDT:PB) da pastagem, demonstrou uma variação entre períodos, em que os meses de junho e julho (5,8 e 6) apresentaram relações inferiores ao mês de agosto $(6,8)$. Segundo Moore et al. (1999), a suplementação protéica aumentaria o consumo voluntário de volumosos, quando a relação entre NDT:PB fosse maior do que 7, por causa de uma quantidade inadequada de nitrogênio na dieta. Durante todos os meses de avaliação, a relação se manteve inferior a 7, isto sugere que a suplementação protéica não seria necessária, o que contraria os melhores desempenhos observados.

Em relação ao desempenho animal, não foi observada interação entre tratamento e período, e o efeito do período de avaliação não foi significativo $(\mathrm{P}>0,05)$. A maioria das variáveis avaliadas no desempenho animal foram influenciadas pelos tratamentos (Tabela 4). O peso vivo inicial (PVI) não foi diferente entre os tratamentos, apesar de terem ocorrido alterações nas médias

Tabela 4. Peso vivo inicial (PVI), ganho médio diário (GMD), ganho de peso vivo por hectare (GPVHA), peso vivo final (PVF) e consumo de suplemento (CSUPL) em novilhos mantidos em campo nativo, suplementados com sal proteinado com uréia (SPU), sal proteinado com amiréia (SPA), sal proteinado com amiréia e levedura (SPAL), e sal mineral (SM) ${ }^{(1)}$.

\begin{tabular}{lccrr}
\hline Variável & SPU & SPA & SPAL & SM \\
\hline PVI $(\mathrm{kg})$ & 263,25 & 254,25 & 257,75 & 251,25 \\
GMD $(\mathrm{kg})$ & $0,159 \mathrm{ab}$ & $0,124 \mathrm{ab}$ & $0,287 \mathrm{a}$ & $0,019 \mathrm{~b}$ \\
GPVHA $(\mathrm{kg})$ & $14,05 \mathrm{ab}$ & $11,36 \mathrm{ab}$ & $27,93 \mathrm{a}$ & $1,08 \mathrm{~b}$ \\
PVF $(\mathrm{kg})$ & $276,44 \mathrm{ab}$ & $264,94 \mathrm{ab}$ & $284,13 \mathrm{a}$ & $252,25 \mathrm{~b}$ \\
CSUPL $\left(\mathrm{kg} \mathrm{dia}^{-1}\right)$ & $0,391 \mathrm{a}$ & $0,412 \mathrm{a}$ & $0,418 \mathrm{a}$ & $0,038 \mathrm{~b}$ \\
\hline
\end{tabular}

${ }^{(1)}$ Médias na mesma linha, com letras iguais, não diferem entre si pelo teste de Tukey a $5 \%$ de probabilidade. 
de PVI, em função do período de adaptação. O ganho médio diário (GMD) dos animais, que receberam os suplementos protéicos sem levedura, não foi diferente do GMD apresentado pelos animais que receberam a suplementação mineral (0,159 kg e 0,124 kg x 0,019 kg); o ganho de peso por hectare apresentou resposta semelhante (Tabela 4). Esses resultados contrastam com os valores apresentados por Lopes et al. (1999), Zanetti et al. (2000) e Moreira et al. (2003), que mostram superioridade da suplementação protéica, em relação à suplementação mineral, no ganho de peso de animais em pastagens de baixa qualidade.

O que poderia explicar a falta de significância entre o desempenho da suplementação protéica e mineral, encontrada nesse experimento, foi o pequeno número de observações utilizadas, juntamente, com um alto coeficiente de variação do GMD dentro dos tratamentos. As fontes de nitrogênio não protéico (NNP) não afetaram o GMD dos animais; os animais suplementados com sais formulados com uréia e amiréia apresentaram GMD de 0,159 kg e 0,124 kg, respectivamente. Esses resultados estão de acordo com outros trabalhos, nos quais não foram observadas diferenças no desempenho de bovinos e ovinos, suplementados com amiréia ou uréia (Seixas et al., 1999; Ezequiel et al., 2001).

A adição de levedura ao sal proteinado, formulado com amiréia, não resultou em diferenças no GMD, em relação aos animais que receberam os suplementos protéicos sem levedura $(0,287 \mathrm{~kg}$ x 0,159 kg e 0,124 kg). Porém, os animais que receberam o sal proteinado com amiréia e levedura, apresentaram GMD 15 vezes superior ao apresentado pelos animais que receberam somente o sal mineralizado $(0,287 \mathrm{~kg}$ x $0,019 \mathrm{~kg})$. O melhor GMD obtido com o suplemento, em que foi incorporada a levedura ativa, pode ser explicado pelo efeito que a levedura tem sobre o aumento na taxa de degradação da fibra (Yoon \& Stern, 1995), e pelo aumento da concentração ruminal de bactérias celulolíticas (Dawson et al., 1990), que possibilita uma maior síntese de proteína microbiana.

Os pesos vivos finais (PVF) dos animais diferiram entre os tratamentos; os animais suplementados com o sal proteinado com amiréia e levedura apresentaram um PVF médio maior do que aqueles suplementados com sal mineral (284,13 kg x 252,25 kg).

O tipo de suplemento utilizado afetou o consumo, os suplementos protéicos com uréia, amiréia, e amiréia mais levedura resultaram em consumos diários médios de: 0,391 kg; 0,412 kg e 0,418 kg, respectivamente, e fo- ram superiores ao consumo do suplemento mineral, que foi de $0,038 \mathrm{~kg}$.

A suplementação com sal proteinado, formulado com amiréia e levedura obteve o maior ganho econômico, durante os noventa dias de suplementação, tendo gerado um lucro bruto, por animal, de R $\$ 14,52$, o que justifica a utilização desse suplemento no período de inverno (Tabela 5). A suplementação com sal proteinado, formulado com uréia, e a suplementação com sal mineral, resultaram em desempenhos semelhantes, com ganho de $\mathrm{R} \$ 0,83$ e perda de $\mathrm{R} \$ 1,18$, respectivamente, por animal, no período. A suplementação com sal proteinado, formulado com amiréia, obteve o pior desempenho econômico entre os tratamentos, tendo gerado um prejuízo de $\mathrm{R} \$ 10,81$, por animal, esse fato é justificado pela incapacidade da melhora do desempenho animal em cobrir o alto custo da amiréia, na formulação desse suplemento.

Considerando-se ganhos médios diários (GMD) de $0,800 \mathrm{~kg}$, no período da primavera, os animais suplementados com o sal proteinado com uréia necessitariam de 17 dias, para recuperar a diferença de ganho de peso, no período experimental, em relação ao sal proteinado com amiréia mais levedura; para os animais suplementados com o sal mineral seriam necessários 32 dias para recuperar essa diferença. Embora o sal proteinado com uréia seja economicamente semelhante ao sal mineral, deve-se observar que o maior peso final dos animais é uma vantagem do sal proteinado com uréia, em relação ao sal mineral, o que resulta em um menor tempo de terminação até o abate, e possibilita, talvez,

Tabela 5. Análise econômica da suplementação de novilhos com sal proteinado com uréia (SPU), sal proteinado com amiréia (SPA), sal proteinado com amiréia e levedura (SPAL), e sal mineral (SM), em relação ao desempenho produtivo, custo de produção e balanço econômico, por animal.

\begin{tabular}{|c|c|c|c|c|}
\hline Características & SPU & SPA & SPAL & SM \\
\hline Peso vivo inicial $(\mathrm{kg})$ & 263,25 & 254,25 & 257,75 & 251,25 \\
\hline Peso vivo final $(\mathrm{kg})$ & 276,44 & 264,94 & 284,13 & 252,25 \\
\hline Ganho período $^{-1}(\mathrm{~kg})$ & 13,19 & 10,69 & 26,38 & 1,00 \\
\hline diário $(\mathrm{kg})$ & 0,147 & 0,119 & 0,293 & 0,011 \\
\hline Consumo de suplemento $\left(\mathrm{g} \mathrm{dia}^{-1}\right)$ & 460,24 & 469,14 & 469,33 & 41,67 \\
\hline Cus & 0,52 & 0,69 & 0,72 & 0,77 \\
\hline $\operatorname{dia}^{-1}(\mathrm{R} \$)$ & 0,24 & 0,32 & 0,34 & 0,0 \\
\hline Custo no período (R\$) & 21,59 & 28,98 & 30,32 & 2,8 \\
\hline Valor do peso vivo $\mathrm{kg}^{-1}(\mathrm{R} \$)$ & 1,70 & 1,70 & 1,70 & 1,70 \\
\hline Valor do ganho diário $(\mathrm{R} \$)$ & 0,249 & 0,202 & 0,498 & 0,019 \\
\hline Valor do ganho no período $(\mathrm{R} \$)$ & 22,419 & 18,169 & 44,838 & 1,700 \\
\hline Margem bruta dia $^{-1}(\mathrm{R} \$)$ & 0,009 & $-0,120$ & 0,161 & $-0,013$ \\
\hline Margem bruta período ${ }^{-1}(\mathrm{R} \$)$ & 0,831 & $-10,812$ & 14,520 & $-1,17$ \\
\hline
\end{tabular}


um preço melhor pelo quilograma do boi, em razão de oferecer o produto, em um período de entre-safra, além de liberar áreas de pastejo para outras categorias.

\section{Conclusões}

1. A suplementação protéica melhora o desempenho animal e a rentabilidade do produtor.

2. A adição de levedura ativa ao suplemento protéico, à base de amiréia, promove maior ganho de peso dos animais, em relação à suplementação com sal mineralizado.

\section{Referências}

ALVES FILHO, D.C.; BERNARDES, R.A.C.; BRONDANI, I.L. Alternativas para a suplementação em campo nativo: avaliação técnica e econômica. In: RESTLE, J. (Ed.). Eficiência na produção de bovinos de corte. Santa Maria: UFSM, 2000. p.117-146.

A.O.A.C. Official methods of analysis. $16^{\text {th }}$ ed. Washington, DC, 1995.

BARCELLOS, J.O.J.; PRATES, E.R.; OSPINA, H. Suplementação mineral de ruminantes nos campos nativos do Rio Grande do Sul: uma abordagem aplicada à pecuária de corte. In: ENCONTRO ANUAL SOBRE NUTRIÇÃO DE RUMINANTES DA UFRGS, 1, 1999, São Gabriel, RGS. Suplementação mineral de bovinos de corte: [anais]. Porto Alegre: Gráfica da UFRGS, 1999. p.81-110. BODINE, T.N.; PURVIS, H.T. Effects of supplemental energy and/ or degradable intake protein on performance, grazing behaviour, intake, digestibility, and fecal and blood indices by beef steers grazed on dormant native tallgrass prairie. Journal of Animal Science, v.81, p.304-317, 2003.

COCHRAN, R.C.; KÖSTER, H.H.; OLSON, K.C.; HELDT, J.S.; MATHIS, C.P.; WOODS, B.C. Supplemental protein sources for grazing beef cattle. In: ANNUAL FLORIDA RUMINANT NUTRITION SYMPOSIUM, 9., 1998, Gainesville. Proceedings. Gainesville: University of Florida, 1998. p.123-136.

DAWSON, K.A.; NEWMAN, K.E.; BOLING, J.A. Effects on microbial supplements containing yeast and lactobacilli on roughagefed ruminal microbial activities. Journal of Animal Science, v.68, p.3392-3398, 1990.

EZEQUIEL, J.M.B.; MATARAZZO, S.V.; SALMAN, A.K.D.; MARTINS JÚNIOR, A.P.; SOARES, W.V.B.; SEIXAS, J.R.C. Digestibilidade aparente da energia e da fibra de dietas para ovinos contendo uréia, amiréia ou farelo de algodão. Revista Brasileira de Zootecnia, v.30, p.231-235, 2001.

IBGE. Censo Agropecuário 1996. Disponível em: http:// www.sidra.ibge.gov.br. Acesso em: maio 2004.

KÖSTER, H.H.; COCHRAN, R.C.; TITGEMEYER, E.C. Effect of increasing degradable intake protein on intake and digestion of low-quality, tallgrass-prairie forage by beef cows. Journal of Animal Science, v.74, p.2473-2481, 1996.
LOPES, H.O.S.; LEITE, G.G.; PEREIRA, E.A.; PEREIRA, G.; SOARES, W.V. Suplementação de bovinos com misturas múltiplas em pastagens de Brachiaria brizantha cv. Marandu no período da seca. Pasturas Tropicales, v.21, p.54-58, 1999.

MATHIS, C.P.; COCHRAN, R.C.; HELDT, J.S.; WOODS, B.C.; ABDELGADIR, L.E.O.; OLSON, K.C.; TITGEMEYER, E.C.; VANZANT, E.S. Effects of supplemental degradable intake protein on utilization of medium-to-low quality forages. Journal of Animal Science, v.78, p.224-232, 2000.

MINSON, D.J. Forage in ruminant nutrition. London: Academic Press, 1990. 483p.

MOORE, J.E.; BRAND, W.E.; KUNKLE, W.E.; HOPKINS, D.I. Effects of supplementation on voluntary forage intake, diet digestibility, and animal performance. In: JOINT MEETING SYMPOSIUM ISSUE, 1999. Abstracts. [s.l:s.n], 1999. p.122-135. MOREIRA, F.B.; PRADO, I.N.; CACATO, U.; ZEOULA, L.M.; WADA, F.Y.; TORII, M.S. Suplementação com sal mineral proteinado para bovinos de corte, em crescimento e terminação, mantidos em pastagem de grama estrela roxa (Cynodon plectostachyrus Pilger) no inverno. Revista Brasileira de Zootecnia, v.32, p.449-455, 2003.

NRC. Nutrient requirements of beef cattle. $7^{\text {th }}$ ed. Washington, DC: National Academy Press, 1996. 242p.

OSPINA, H.O.; MEDEIROS, F.S. Suplementação a pasto: uma alternativa para produção de novilho precoce. In: SIMPÓSIO INTERNACIONAL DA CARNE BOVINA: DA PRODUÇÃO AO MERCADO CONSUMIDOR, 2003, São Borja. Anais. São Borja, 2003. p.83-115.

POPPI, D.P.; HUGHES, T.P.; L'HUILLIER, J.L. Intake of pastures by grazing ruminants. In: NICOL, A.M. (Ed.). Feeding livestock on pasture. New Zealand: N. Zeal. Soc. An. Prod., 1987. p.55-64. (Occasional Publication, n.10).

SALOMONI, E.; BORBA, E.R.; DEL DUCA, L.O.A.; LEAL, J.J.B. Idade e peso à puberdade em fêmeas de corte puras e cruzas em campo natural. Pesquisa Agropecuária Brasileira, v.23, p.11711179, 1988.

SEIXAS, J.R.C.; EZEQUIEL, J.M.B.; ARAUJO, W.A.; RESENDE, F.D.; MARTINS JUNIOR, A.; KRONKA, S.N.; SILVA, L.D.F.; DOURADO, J.B.; SOARES, W.B.V. Desempenho de bovinos confinados alimentados com dietas à base de farelo de algodão, uréia ou amiréia. Revista Brasileira de Zootecnia, v.28, p.432-438, 1999.

SOEST, P.J. van. Nutritional ecology of the ruminant. Ithaca: Cornell University, 1994. 476p.

SOEST, P.J. van; ROBERTSON, J.B. Analysis of forages and fibrous foods: a laboratory manual for animal science. Ithaca: Cornell University, 1985. 202p.

YOON, I.K.; STERN, M.D. Influence of direct-feed microbials on ruminal microbial fermentation and performance of ruminants: a review. Asian-Australian Journal of Animal Science, v.8, p.533555, 1995.

ZANETTI, M.A.; RESENDE, J.M.L.; SCHALCH, F.; MIOTTO, C.M. Desempenho de novilhos consumindo suplemento mineral proteinado convencional ou com uréia. Revista Brasileira de Zootecnia, v.29, p.935-939, 2000. 